\title{
Penerapan Model Pembelajaran Kooperatif Teknik Kancing Gemerincing untuk Meningkatkan Aktivitas Siswa
}

\author{
*1Muhaiminul Azizah, 2Syifaul Gummah, ${ }^{3}$ Baiq Azmi Sukroyanti \\ 1,2\&3Program Studi Pendidikan Fisika, FPMIPA, IKIP Mataram, J1. Pemuda No. 59A \\ Mataram, Indonesia 83125 \\ Email: enulajja894@gmail.com
}

\begin{tabular}{|c|c|}
\hline ARTICLE INFO & ABSTRACT \\
\hline Article history & [Title: The Implementation of the Cooperative Learning Model with Jingle \\
\hline Received: March 2019 & Button Techniques to Increase Student Activities]. This study aims to improve the \\
\hline Revised: April 2019 & learning activities of students of class VIII Madrasah Tsanawiyah (MTs) NW SIKUR \\
\hline Accepted: May 2019 & by applying cooperative learning models of clanging button techniques. This type of \\
\hline Published: June 2019 & research is a classroom action research conducted in 2 cycles. The subjects in this study \\
\hline Кей & $\begin{array}{l}\text { were students of class VIII MTS NW SIKUR, amounting to } 37 \text { people. Student and } \\
\text { teacher learning activity data is collected through observation sheets. From the results }\end{array}$ \\
\hline Cooperative Learning; & of the study it was found that the total score of student activity in the 2 cycles always \\
\hline Jingle Buttoned Technique; & increased. In cycle I the score of student activity was 2.88 with the category of quite \\
\hline Activity & active while in cycle II the score of student activity was 3.41 with the active category. \\
\hline & Based on the overall results of this study it can be concluded that the application of the \\
\hline & $\begin{array}{l}\text { clanking button learning cooperative model can increase the learning activities of } \\
\text { students of class VIII Madrasah Tsanawiyah NW SIKUR in the academic year } \\
\text { 2017/2018. }\end{array}$ \\
\hline
\end{tabular}

\begin{tabular}{|c|c|}
\hline INFO ARTIKEL & ABSTRAK \\
\hline Sejarah Artikel & Penelitian ini bertujuan untuk meningkatkan aktivitas belajar siswa kelas VIII \\
\hline Dikirim: Maret 2019 & Madrasah Tsanawiyah (MTs) NW SIKUR dengan menerapkan model \\
\hline Direvisi: April 2019 & pembelajaran kooperatif teknik kancing gemerincing. Jenis penelitian yang \\
\hline Diterima: Mei 2019 & digunakan adalah penelitian tindakan kelas yang dilakukan dalam 2 siklus. \\
\hline Dipublikasi: Juni 2019 & $\begin{array}{l}\text { Subyek dalam penelitian ini adalah siswa kelas VIII MTs NW SIKUR yang } \\
\text { berjumlah } 37 \text { orang. Data aktivitas belajar siswa dan guru dikumpulkan }\end{array}$ \\
\hline Kata kunci & melalui lembar observasi. Dari hasil penelitian diperoleh bahwa jumlah skor \\
\hline Pembelajaran Kooperatif; & aktivitas siswa dalam 2 siklus selalu mengalami peningkatan. Pada siklus I skor \\
\hline Teknik Kancing & aktivitas siswa adalah 2,88 dengan kategori cukup aktif sedangkan pada siklus \\
\hline Gemerincing; & II skor aktivitas siswa 3,41 dengan kategori aktif. Berdasarkan hasil \\
\hline Aktivitas & $\begin{array}{l}\text { keseluruhan penelitian ini dapat disimpulkan bahwa penerapan model } \\
\text { pembelajaran kooperatif teknik kancing gemerincing dapat meningkatkan } \\
\text { aktivitas belajar siswa kelas VIII Madrasah Tsanawiyah NW SIKUR tahun } \\
\text { pelajaran } 2017 / 2018 \text {. }\end{array}$ \\
\hline
\end{tabular}

How to Cite this Article? Azizah, M., Gummah, S., \& Sukroyanti, B., A. (2019). Penerapan Model Pembelajaran Kooperatif Teknik Kancing Gemerincing untuk Meningkatkan Aktivitas Siswa. Jurnal Penelitian dan Pengkajian Ilmu Pendidikan:e-Saintika, 2(2), 127-134. 


\section{PENDAHULUAN}

Perkembangan dan kemajuan zaman ini semakin pesat oleh karena itu Guru dituntut untuk memiliki kemampuan merancang dan menggunakan model pembelajaran yang dapat menumbuhkan cara berpikir siswa agar menjadi lebih kritis dan kreatif. Pandangan siswa tentang mata pelajaran fisika sebagai momok masih banyak didapatkan, pandangan seperti ini yang mengakibatkan siswa menjadi kurang aktif dan hasil belajarnya kurang memuaskan. Siswa yang merasa bahwa fisika menanggapi setiap pelajaran yang diajarkan khususnya pada mata pelajaran sebagai momok ini mungkin disebabkan oleh berbagai hal seperti cara penyampaian materi dari guru yang monoton. Hal ini mengindikasikan bahwa keberhasilan pembelajaran fisika masih jauh dari harapan. Siswa tidak lagi harus dibuat menjadi pasrah sebagai penerima informasi dari guru. Lalu pertanyaannya adalah bagaimana peran guru di dalam melaksanakan proses pembelajaran di kelas? Apakah model pembelajaran yang diterapkan guru dapat membangkitkan minat dan aktivitas siswa ketika belajar?

Model pembelajaran yang efektif dan menarik adalah model pembelajaran yang memiliki nilai relevansi dengan pencapaian daya fisika, memberi peluang untuk bangkitnya kreativitas, mampu mengembangkan suasana belajar mandiri dan menarik perhatian peserta didik. Model pembelajaran seperti inilah yang seyogyanya diterapkan oleh guru untuk membangkitkan minat dan aktivitas siswa untuk belajar fisika. Salah satu teknik pembelajaran yang dapat melibatkan siswa aktif dalam proses pembelajaran adalah teknik kancing gemerincing (Huda, 2012).

Teknik kancing gemerincing merupakan teknik dalam menerapkan model pembelajaran kooperatif yang memiliki tujuan utama untuk mengatasi pemerataan kesempatan belajar setiap siswa. Siswa didorong untuk beraktivitas dalam belajar yakni dengan mengemukakan ide atau pendapatnya serta mendengarkan pendapat rekannya yang lain atau dengan kata lain untuk merangsang siswa berpikir dan berbuat tanpa harus tergantung pada rekannya yang lain.

Model Pembelajaran Kooperatif adalah model pembelajaran di mana siswa belajar dalam kelompok-kelompok kecil yang memiliki tingkat kemampuan yang berbeda. Unsur model pembelajaran kooperatif harus diterapkan yaitu (1) saling ketergantungan positif, (2) tanggung jawab perseorangan, (3) tatap muka antar kelompok, (3) interaksi antar anggota, (4) evaluasi proses kelompok (Isjoni, 2007; Slavin, 2009).

Teknik kancing gemerincing bisa digunakan dalam semua mata pelajaran dan untuk semua tingkatan usia anak didik. Kegiatan dalam Kancing Gemerincing yaitu masing-masing anggota kelompok mendapatkan kesempatan untuk memberikan kontribusi mereka dan mendengarkan pandangan dan pemikiran anggota lain. Keunggulan lain dari teknik ini adalah untuk mengatasi hambatan pemerataan kesempatan yang sering mewarnai kerja kelompok (Slavin, 2009). Dalam banyak kelompok, sering ada anggota yang terlalu dominan dan banyak bicara. Sebaliknya, juga ada anggota yang pasif dan pasrah saja pada rekannya yang lebih dominan. Dalam situasi seperti ini, pemerataan tanggung jawab dalam kelompok bisa tidak tercapai karena anggota yang pasif 
akan terlalu menggantungkan diri pada rekannya yang dominan. Teknik belajar mengajar Kancing Gemerincing memastikan bahwa setiap siswa mendapatkan kesempatan untuk berperan serta (Huda, 2012). Hal yang menarik dan penting dalam teknik ini adalah merangsang siswa untuk berpikir dan mendorong mereka untuk mengemukakan pendapat, sehingga ada tanggung jawab bagi siswa untuk terlibat aktif dalam kegiatan pembelajaran.

Langkah-langkah pembelajaran kooperatif dengan teknik kancing gemerincing dijabarkan Anita (2008) yaitu (1) guru menyiapkan satu kotak kecil berisi kancing-kancing (atau benda kecil lainnya), (2) sebelum kelompok memulai tugasnya, setiap siswa masing-masing kelompok mendapatkan 2 atau 3 buah kancing (jumlah kancing tergantung pada sukar tidaknya tugas yang diberikan), (3) setiap kali seorang siswa berbicara atau mengeluarkan pendapat, dia harus menyerahkan salah satu kancingnya dan meletakkannya di tengahtengah, (4) jika kancing yang dimiliki siswa habis, dia tidak boleh berbicara lagi sampai semua rekannya juga menghabiskan kancingnya, dan (5) jika semua kancing sudah habis, sedangkan tugas belum selesai, kelompok boleh mengambil kesepakatan untuk membagi-bagi kancing lagi dan mengulangi prosedurnya kembali.

Hasil penelitian terkait efektifitas model pembelajaran kooperatif dalam pembelajaran disampaikan oleh beberapa peneliti seperti Sumiyati dkk (2017) menyatakan terdapat perbedaan hasil belajar siswa menggunakan model pembelajaran kooperatif tipe two-stay two-stray dengan metode konvesional pada mata pelajaran IPS terpadu. Berbeda dengan pernyataan tersebut, Khotimah dkk (2017) menyatakan tidak ada pengaruh signifikan pembelajaran kooperatif dengan teknik listening team terhadap hasil belajar IPS siswa. Sriwahyuningsih dkk (2018) menyatakan bahwa ada pengaruh model pembelajaran kooperatif tipe make a macth dengan permainan rangking one physical terhadap motivasi dan hasil belajar siswa. Di pihak lain Pour dkk (2018) menemukan adanya pengaruh model pembelajaran talking stick terhadap keaktifan belajar siswa. Lebih lanjut Bobo (2018) juga menyatakan ada pengaruh model pembelajaran kooperatif tipe thinkpair-share terhadap hasil belajar siswa. Penelitian ini bertujuan untuk meningkatkan aktivitas belajar siswa menggunakan model pembelajaran kooperatif teknik kancing gemerincing.

\section{METODE}

Jenis penelitian ini adalah penelitian tindakan kelas (PTK). Penelitian tindakan kelas adalah suatu penelitian tindakan (action research) yang dilakukan oleh guru sekaligus sebagai peneliti di kelasnya atau bersama-sama dengan orang lain (kolaborasi) dengan jalan merancang, melaksanakan dan merefleksikan tindakan secara kolaboratif dan partisipatif yang bertujan untuk memperbaiki atau meningkatkan mutu (kualitas) proses pembelajaran di kelasnya melalui suatu tindakan (treatment) tertentu dalam suatu siklus (Kunandar, 2010). Selanjutnya menurut (Takari, 2010) penelitian tindakan kelas adalah suatu penelitian yang dilakukan secara sistematis reflektif terhadap berbagai tindakan yang dilakukan oleh guru yang sekaligus sebagai peneliti, sejak disusunya suatu perencanaan sampai penilaian terhadap tindakan nyata di 
dalam kelas yang berupa kegiatan belajar-mengajar untuk memperbaiki kondisi pembelajaran yang dilakukan. Data aktivitas guru dan siswa dalam penelitian ini dikumpulkan menggunakan lembar observasi aktivitas guru dan siswa.

\section{HASIL DAN PEMBAHASAN}

Peningkatan aktivitas siswa dan guru dalam penelitian ini disajikan pada Gambar 1, Gambar 2, Gambar 3, dan Gambar 4 berikut.

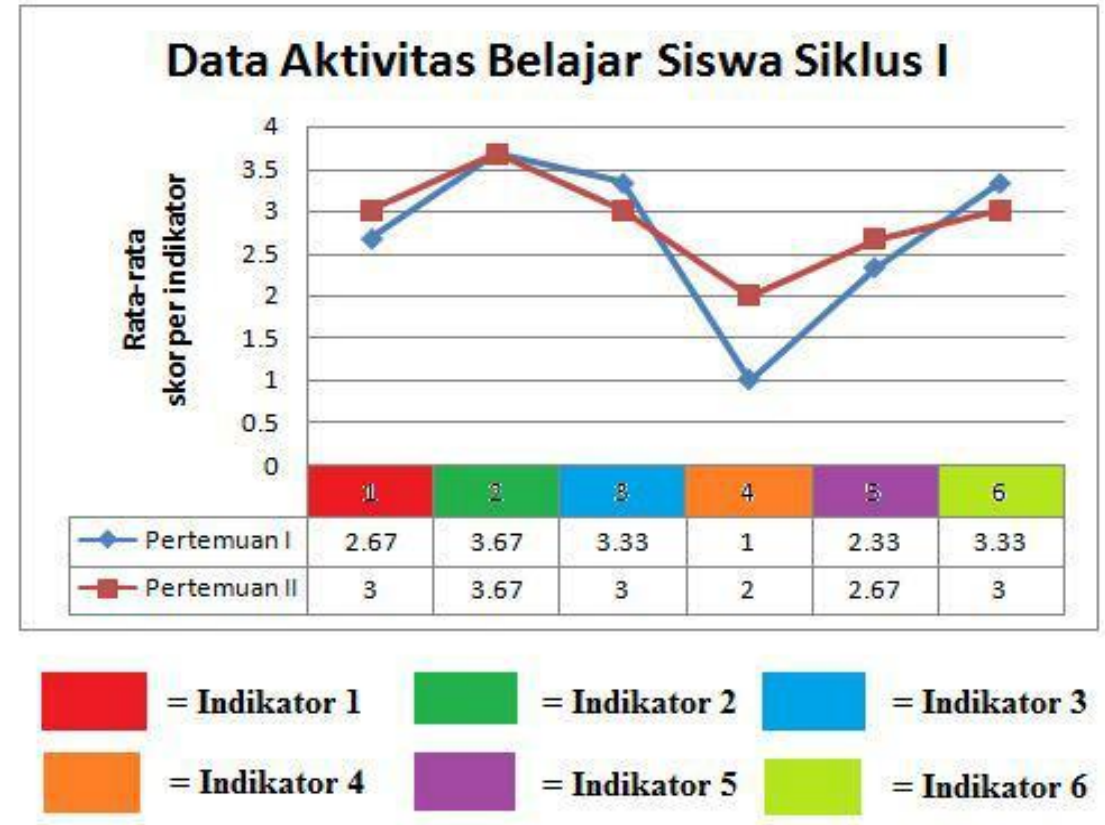

Gambar 1. Aktivitas belajar siswa siklus I

Berdasarkan Gambar 1 dapat dilihat bahwa hasil observasi aktivitas belajar siswa pada pertemuan pertama total skor yang diperoleh adalah 16,33 dengan kategori sangat aktif dan pada pertemuan kedua total skor yang diperoleh adalah 17,34 dengan kategori sangat aktif juga. Hal ini berarti indikator kerja untuk aktivitas siswa pada siklus I sudah tercapai.

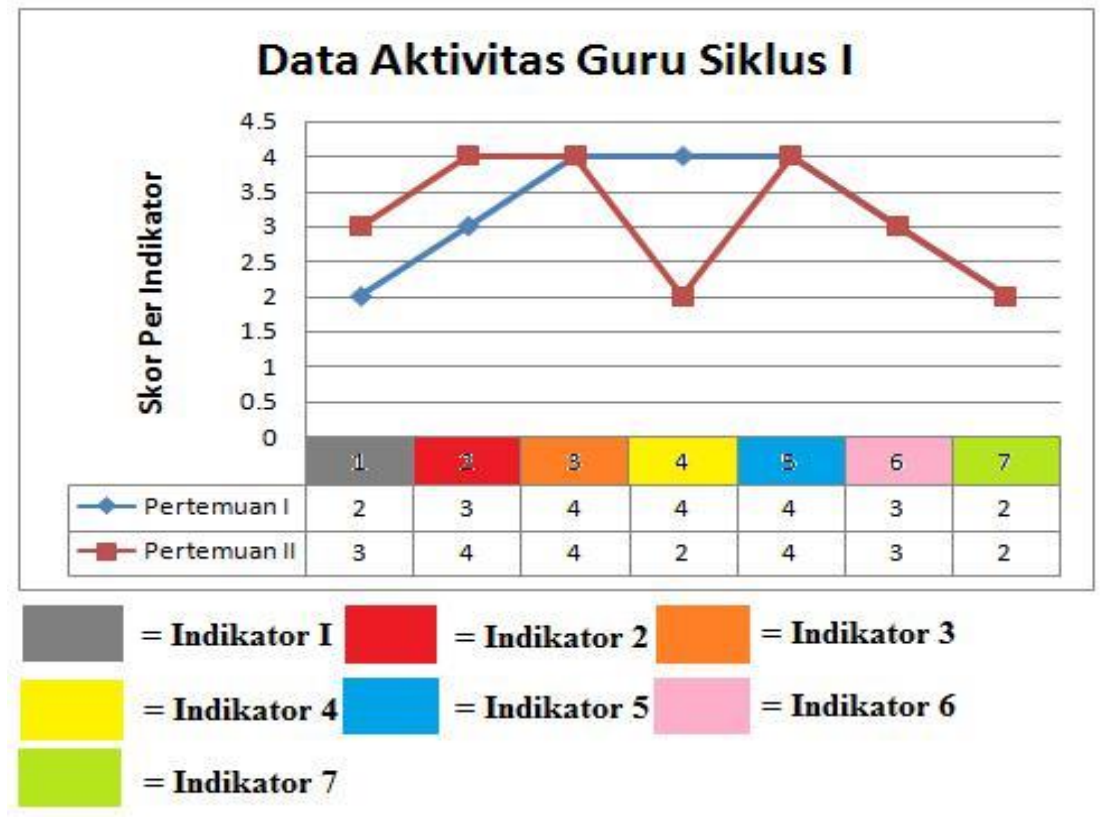

Gambar 2. Aktivitas belajar guru siklus I 
Berdasarkan Gambar 2, observasi aktivitas mengajar guru pada pertemuan pertama dan pertemuan kedua total skor yang diperoleh sama yaitu 22. Hal ini berarti bahwa pelaksanaan kegiatan guru tergolong dalam kriteria baik. Sehingga dapat diketahui bahwa aktivitas mengajar guru pada siklus I dikategorikan aktif dengan rata-rata skor 3,14.

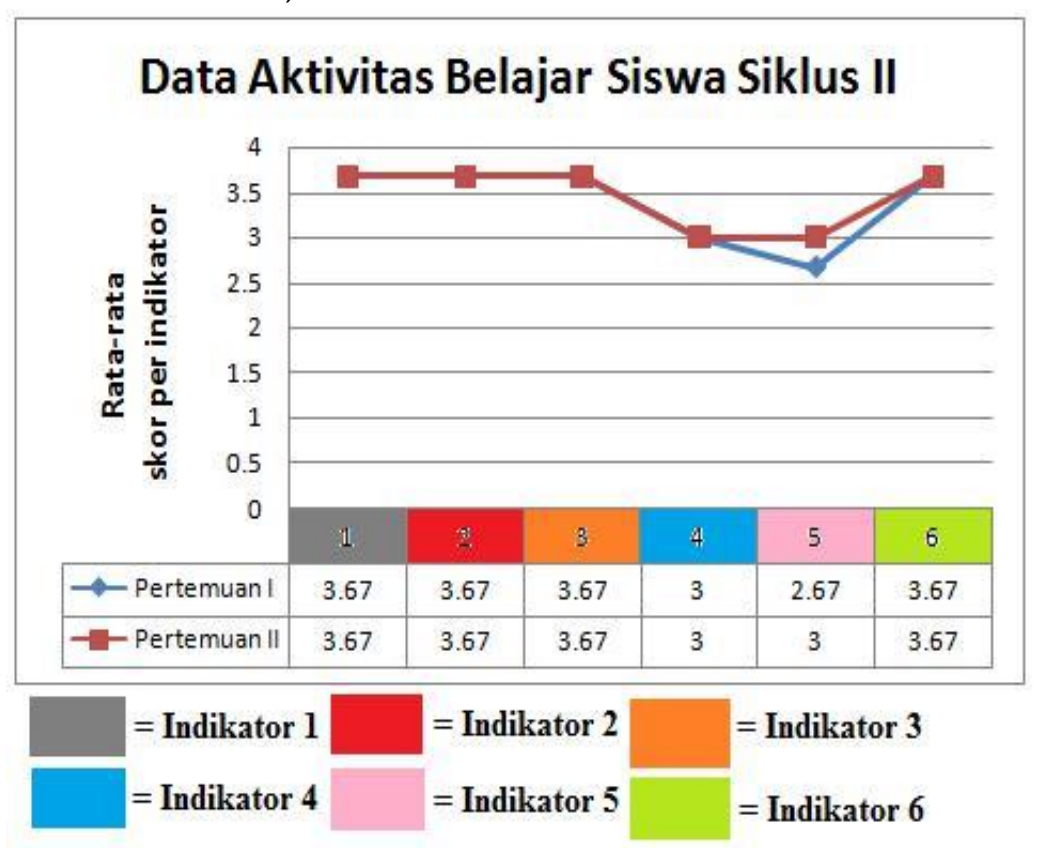

Gambar 3. Aktivitas belajar siswa siklus II

Gambar 3 menunjukkan aktivitas belajar siswa sudah meningkat di mana pada pertemuan pertama total skor yang diperoleh adalah 20,35 dengan kategori aktif dan pada pertemuan kedua total skor yang diperoleh adalah 24,01 dengan kategori aktif juga. Hal ini berarti indikator kerja untuk aktivitas siswa pada siklus II sudah tercapai.

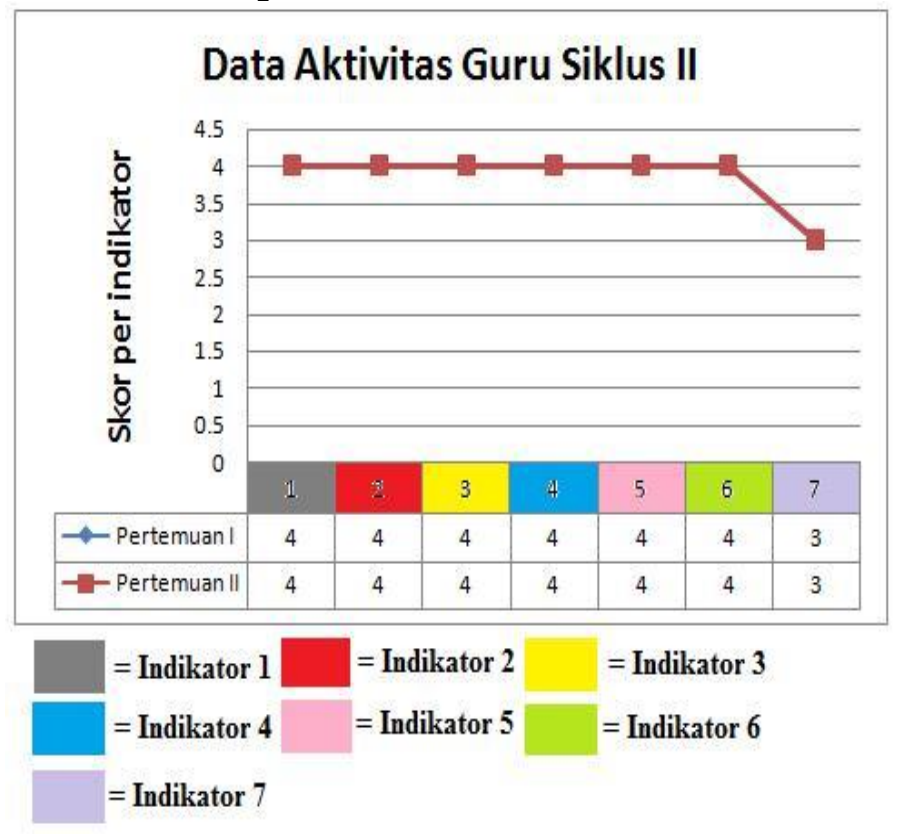

Gambar 4. Aktivitas belajar guru siklus II 
Gambar 4 menunjukkan bahwa aktivitas mengajar dimana pada pertemuan pertama dan pertemuan kedua. Kedua total skor yang diperoleh sama yaitu 27 dengan kategori sangat aktif dengan rata-rata skor adalah 3,85. Berdasarkan hasil analisis pelaksanaan siklus I terlihat bahwa aktivitas guru berkategori aktif dan aktivitas belajar siswa berkategori aktif pada setiap pertemuan namun masih kurang pada beberapa indikator seperti disajikan pada Gambar 1 dan Gambar 2. Hal tersebut disebabkan karena kekurangan-kekurangan yang terjadi selama proses pembelajaran dalam menerapkan model pembelajaran kooperatif teknik kancing gemerincing yang dilakukan oleh guru maupun siswa. Kekurangankekurangan tersebut antara lain: kurang memberikan bimbingan dan arahan kepada masing-masing kelompok dalam melakukan diskusi, kurang memotivasi siswa dalam kelompok, masih kurangnya interaksi siswa dalam kelompoknya sehingga kegiatan diskusi pada kelompok tersebut masih didominasi siswa yang pandai saja, dan siswa masih takut bertanya ketika ada materi yang belum di pahami, siswa dalam mengemukakan pendapatnya masih kurang optimal. Kehadiran seorang guru dalam proses belajar mengajar atau pengajaran masih tetap memegang peranan penting. Peranan guru dalam proses pengajaran belum dapat digantikan oleh mesin, radio, tape recorder, ataupun komputer yang paling modern sekalipun. Masih terlalu banyak unsur manusiawi seperti sikap, sistem nilai, perasaan, motivasi, kebiasaan, dan lain-lain yang merupakan hasil dari proses pembelajaran (Daryanto, 2010)

Kekurangan tersebut berdampak pada kurang maksimalnya kegiatan belajar mengajar sehingga perlu dilakukan perbaikan pada siklus II. Selanjutnya berdasarkan hasil analisis pelaksanaan siklus II diperoleh bahwa aktivitas guru berkategori sangat aktif dan aktivitas siswa berkategori aktif pada setiap pertemuan dengan pencapaian indikator penilaian yang lebih konsisten. Beberapa hal yang menyebabkan terjadinya peningkatan aktivitas belajar siswa antara lain suasana kelas menjadi menyenangkan dengan adanya tanya jawab antara guru dan siswa, guru memberikan perhatian dan bimbingan yang merata pada semua kelompok saat diskusi agar mereka termotivasi dalam pembelajaran, siswa melaksanakan dengan baik kegiatan pembelajaran, lebih banyak siswa yang aktif bukan hanya didominasi oleh siswa yang pandai saja, keingintahuan siswa lebih banyak, serta siswa tidak segan-segan untuk mengemukakan pendapat kepada temannya. Hasil tersebut sejalan dengan pernyataan Hamalik (2008) bahwa pengajaran merupakan interaksi mengajar dan belajar. Pengajaran berlansung sebagai suatu proses saling pengaruh-mempengaharui dalam bentuk hubungan interaksi antara guru dan siswa.

Berdasarkan uraian tersebut dapat dinyatakan bahwa pembelajaran dengan teknik kancing gemerincing mampu meningkatkan aktivitas belajar siswa. Hal ini disebabkan oleh model pembelajaran kooperatif teknik kancing gemerincing mendorong siswa untuk berani mengemukakan pendapat ketika diskusi kelompok dan tidak serta merta hanya sebagai pendengar dan penerima hasil diskusi sehingga siswa akan lebih terlibat dalam pembelajaran. Terlibatnya siswa dalam proses pembelajaran membuat siswa mengingat pelajaran lebih lama jika dibandingkan hanya sebagai pendengar. Terlebih dengan memberikan 
penghargaan kelompok yang merupakan salah satu ciri khas model pembelajaran ini menjadikan siswa lebih termotivasi untuk belajar.

\section{KESIMPULAN}

Berdasarkan hasil penelitian dan pembahasan, dapat dikemukakan bahwa model pembelajaran kooperatif teknik kancing gemerincing dapat meningkatkan aktivitas belajar siswa kelas VIII Madrasah Tsanawiyah NW Sikur tahun pelajaran 2017/2018 pada pokok bahasan getaran dan gelombang.

\section{SARAN}

Hasil penelitian ini hanya terbatas pada observasi peningkatan aktivitas belajar siswa menggunakan model pembelajaran kooperatif teknik kancing gemerincing pada materi getaran dan gelombang sehingga perlu penelitian lanjutan untuk mengerahui efektifitas model tersebut pada komponen hasil belajar lainnya pada materi yang lebih luas

\section{DAFTAR PUSTAKA}

Anita, L. (2010). Cooperative Learning (Mempraktekan Cooperative Learning di RuangRuang Kelas). Jakarta: Grasindo

Arifin, Z. (2011). Evaluasi Pembelajaran. Bandung: PT Remaja Rosdakarya

Bobo, P., S. (2018). Implementasi Model Pembelajaran Think Pair Share untuk Meningkatkan Hasil Belajar Siswa. Jurnal Penelitian dan Pengkajian Ilmu Pendidikan: e-Saintika, 2(1), 49-54.

Daryanto. (2010). Belajar dan Mengajar. Bandung: CV. Yrama Widya

Hamalik, O. (2008). Kurikulum dan Pembelajaran. Jakarta: Bumi Aksara

Huda, M. (2012). Cooperative Learning (Metode, Teknik, Struktur dan Model Penerapan) Isjoni, H. (2007). Cooperative Learning Mengembangkan Kemampuan Belajar Kelompok. Bandung: Alfabeta

Karlina, I. (2008). Pembelajaran Kooperatif (Cooperative Learning) sebagai Salah Satu Strategi Membangun Pengetahuan Siswa. http://www.sdbinatalenta.com/artikel Ina.pdf.download/7/10/2008 diakses pada tanggal 23 januari 2012.

Khotimah, H., Sumiyati \& Nurjannah. (2017). Pengaruh Teknik Pembelajaran Listening Team Terhadap Hasil Belajar IPS Siswa. Jurnal Penelitian dan Pengkajian Ilmu Pendidikan: e-Saintika, 1(1), 1-10.

Pour, D., N., Herayanti, L., \& Sukroyanti, B., A. (2018). Pengaruh Model Pembelajaran Talking Stick terhadap Keaktifan Belajar Siswa. Jurnal Penelitian dan Pengkajian Ilmu Pendidikan: e-Saintika, 2(1), 36-40.

Sagala, S. (2008). Konsep dan Makna Pembelajaran. Bandung: Alfabeta

Sardiman, (2011). Interaksi dan Motivasi Belajar Mengajar. Jakarta: Rajawali Pers

Slameto. (2010). Belajar dan Faktor-Faktor yang Mempengaruhinya. Jakarta: Rineka Cipta

Slavin, R.E. (2009). Cooperative Learning (Teori, Riset dan Praktik). Bandung: Nusa Media

Sriwahyuningsih, D., Ahzan, S., \& Habiburrahman, L. (2018). Pengaruh Model Pembelajaran Koperatif Tipe Make A Macth dengan Permainan Rangking One 
Physical Terhadap Motivasi dan Hasil Belajar Siswa. Jurnal Penelitian dan Pengkajian Ilmu Pendidikan: e-Saintika, 2(1), 29-35.

Sugiyono, (2010). Metode Penelitian Pendidikan Pendekatan Kuantitatif. Bandung: Alfabeta

Sumiyati., Nurjannah., \& Khotimah, H. (2017). Perbandingan Hasil Belajar IPS Terpadu Model Pembelajaran Kooperatif Tipe Two Stay-Two Stray Dengan Metode Ceramah. Jurnal Penelitian dan Pengkajian Ilmu Pendidikan: e-Saintika, 1(1), 33-44. 